\title{
Environmental Effects on the Elastic Moduli of Composite Materials
}

\author{
Chi-Hung Shen and George S. Springer \\ Department of Mechanical Engineering \\ The University of Michigan \\ Ann Arbor, Michigan 48109
}

(Received May 9, 1977)

\begin{abstract}
The buckling moduli of Thornel 300/liberite 1034 graphite epoxy composites were measured at temperatures ranging from $105 \mathrm{~K}$ to $422 \mathrm{~K}$ and at moisture contents ranging from $0 \%$ (dry) to $1.5 \%$ (fully saturated). The measurements were made using $0^{\circ}, 90^{\circ}$ and $\pi / 4$ laminates. A survey was also made of the existing data showing the effects of temperature and moisture content on the tensile modulus and the compressive modulus of different composite materials.
\end{abstract}

\section{SCOPE}

T N ORDER TO utilize the full potential of composite materials their performance during and after exposure to high temperature and high humidity environments must be known. One of the most important parameters in the design of composite elements and structures is the elastic modulus. The effects of temperature and moisture content on tensile $\left(E_{t}\right)$ and compressive $\left(E_{c}\right)$ moduli have been studied in the past. The objective of this investigation was to evaluate the changes in the buckling modulus $\left(E_{b}\right)$ of composite materials exposed to air in which the temperature ranged from $195 \mathrm{~K}$ to $450 \mathrm{~K}$ and the moisture content from $0 \%$ (dry) to $1.5 \%$ (fully saturated). The changes in the buckling modulus were measured by performing buckling tests on. Thornel 300/Fiberite 1034 graphite epoxy composites using $0^{\circ}, \pi / 4$ and $90^{\circ}$ lay-ups. A summary was also made of the existing data. This summary, together with the present results, was used to assess the influence of the temperature and the moisture content on the elastic moduli of composite materials. 


\section{CONCLUSIONS}

On the basis of both the present data (for buckling modulus) and the existing data (for tensile and compressive moduli, Table 1) the following general conclusions may be drawn.

Table I. Summary of Experimental Data on the Effects of Moisture and Temperature on the Elastic Modulus of Composite Materials

\begin{tabular}{|c|c|c|c|c|c|c|c|}
\hline \multirow{3}{*}{ Composite } & \multirow{3}{*}{ Reference } & \multicolumn{6}{|c|}{ Laminate Lay-Up Orientation } \\
\hline & & \multicolumn{3}{|c|}{$0^{\circ}$} & \multirow{2}{*}{$\frac{\pi / 4}{\text { Terap }}$} & \multicolumn{2}{|c|}{$90^{\circ}$} \\
\hline & & Moist & Temp & Moist & & Ho1st & Temp \\
\hline \multicolumn{8}{|c|}{ BUCKLING TEST } \\
\hline Thornel juo/riberite 1034 & Shen \& Springer 1977 & $\mathrm{~N}$ & N & $\mathrm{N}$ & N & 5 & $s$ \\
\hline \multicolumn{8}{|c|}{ TENSILE TEST } \\
\hline \multirow[t]{3}{*}{ Hercules AS- $5 / 3501$} & Browning, et al 1976 & $\mathrm{~L}$ & N & L & $N$ & $s$ & $\mathrm{~s}$ \\
\hline & Verette $1975[6]$ & $N$ & $\mathrm{~N}$ & $\mathrm{~N}$ & - & 5 & s \\
\hline & Kerr et al 1975 [7] & - & $N$ & - & $N$ & - & - \\
\hline \multirow[t]{2}{*}{ Thornel $300 /$ Narmco 5208} & Hofer et al 1975 [8] & $\mathrm{N}$ & $\mathrm{N}$ & $\mathrm{N}$ & N & N & $\mathrm{N}$ \\
\hline & Husman 1976 [9] & - & - & - & - & 5 & 5 \\
\hline Modmor II/Nartnco 5206 & Hofer et al $1974[10]$ & $\mathrm{N}$ & $\mathrm{N}$ & $\mathrm{N}$ & $\mathrm{N}$ & s & $s$ \\
\hline Courtaulds HMS/Hercules $3002 \mathrm{M}$ & Hofer et al 1974 [10] & $\mathrm{N}$ & $\mathrm{N}$ & $\mathrm{N}$ & $\mathrm{N}$ & $\mathrm{r}$ & s \\
\hline$H T-S / E R L A-4617$ & Browning 1972 [11] & - & - & $\mathrm{N}$ & s & - & - \\
\hline HT-S/Fiberite $X-911$ & Browning 1972 [11] & - & - & $\mathrm{N}$ & $N$ & - & - \\
\hline $\mathrm{HT}-\mathrm{S} / \mathrm{UCC} \quad \mathrm{X}-2546$ & Browning 1972 [11] & - & - & $\mathbf{N}$ & $\mathrm{L}$ & - & - \\
\hline PRD-49/ERLB-4617 & Hanson 1972 [12] & - & s & - & - & - & - \\
\hline $\mathrm{HT}-\mathrm{S} /\left(8183 / 137-\mathrm{NDA}^{-B F_{3}}: \quad \mathrm{MEA}\right)$ & Hert2 1973 [13] & - & - & - & - & N & $\mathbf{s}$ \\
\hline \multicolumn{8}{|c|}{ TENSILE TEST } \\
\hline HTT-S/IYysol ADX-516 & Browning 1972 (11] & - & - & $\mathrm{N}$ & s & - & - \\
\hline ITT-S/710 Polyimide & kerr et al 1975 [7] & - & $\mathrm{N}$ & - & N & - & - \\
\hline IIT-S/P1.3N folyimide & Browning $1972\{11\}$ & - & - & - & L & - & - \\
\hline Boron/אYCO 5505 & llofer et al 1974 [10] & $\mathrm{N}$ & $\mathrm{N}$ & N & N & s & $s$ \\
\hline Boron/Nurmeo 5505 & Browning 1972 [11] & - & - & N & $N$ & - & - \\
\hline \multicolumn{8}{|c|}{ COMPRESSIVE TEST } \\
\hline Hercules AS-5/3501 & Verette 1975 [6] & $\mathrm{N}$ & $\mathrm{N}$ & - & - & L & $s$ \\
\hline Thornel $300 /$ Narmco 5208 & Hofer et al 1975 [8] & $\mathrm{L}$ & $\mathrm{N}$ & N & N & L & $\mathrm{N}$ \\
\hline Modmor [I/Normco 5206 & liofer et al $1974 \quad[10]$ & $N$ & $\mathrm{~N}$ & N & N & s & s \\
\hline Courtaulds HMS/Hercules $3002 \mathrm{M}$ & Hofer et al 1974 [10] & $\mathrm{N}$ & $\mathrm{N}$ & N & N & $s$ & s \\
\hline Boron/AVCO $\$ 505$ & Hofer et al 1974 [10] & $\mathbf{N}$ & $\mathbf{N}$ & $\mathrm{N}$ & $\mathrm{N}$ & $\mathrm{s}$ & s \\
\hline
\end{tabular}

\footnotetext{
a) $\quad N=$ Negligible effect

b) L $=$ Littlo effect $(<30 t)$

c) $S=$ Strong effect $(>30 \%)$
} 


\section{Temperature Effects}

(a) For $0^{\circ}$ and $\pi / 4$ laminates the temperature (in the range of $200 \mathrm{~K}$ to $450 \mathrm{~K}$. has a negligible effect on the elastic moduli regardless of the moisture content of the material.

(b) For $90^{\circ}$ laminates an increase in temperature causes a decrease in the elastic moduli. The decrease in the modulus depends upon both the temperature and the moisture content. For an increase in temperature from $300 \mathrm{~K}$ to $450 \mathrm{~K}$ the elastic modulus may decrease by as much as 50 to 90 percent.

\section{Moisture Effects}

(a) For $0^{\circ}$ and $\pi / 4$ laminates there appears to be very little change in the elastic moduli over the entire spectrum of moisture content from dry to fully saturated This conclusion appears to be valid regardless of temperature in the range $200 \mathrm{~K} \mathrm{tC}$ $450 \mathrm{~K}$.

(b) For $90^{\circ}$ laminates the elastic moduli decrease considerably with increase in the moisture content. The decrease in the modulus depends both on the moisture content and on the temperature. The decrease in the value of the modulus may be as high as 50 to 90 percent.

(c) In the tests reported here the moisture distribution was nonuniform inside the specimens. For $0^{\circ}$ and $\pi / 4$ specimens the variations encountered in the moisture distribution do not appear to affect the results significantly. For $90^{\circ}$ specimens the moisture distribution may influence the absolute value of the buckling moduli, but is unlikely to affect the trend in the data.

\section{Additional Considerations}

(a) The values of the elastic moduli obtained by tensile, compressive and buck. ling tests are usually different. However, the changes in the moduli caused by changes in temperature and moisture content are nearly the same for all three moduli. Therefore, the conclusions stated in points 1 and 2 above are valid for all three elastic moduli.

(b) The above conclusions depict the general trend in the data. The precise effects of the temperature and the moisture content on a particular composite material must be evaluated from the relevant data. $\Lambda \pm 20$ percent scatter in the data is quite common. This scatter must be borne in mind when applying the data.

\section{EXPERIMENTAL}

All buckling measurements in this study were made with 8 ply T300/1034 specimens of thickness $h=0.9 \mathrm{~mm}$ and width $b=4.76 \mathrm{~mm}$. Different length specimens were used in the tests, the lengths ranging from $36 \mathrm{~mm}$ to $318 \mathrm{~mm}$. The test specimens were cut from $0.66 \mathrm{~m} \times 0.66 \mathrm{~m}$ autoclave cured panels which were fabricated from $30.5 \mathrm{~cm}$ (12 in) prepreg (Fiberite Corp.) using standard lay-up and 
vacuum bagging procedures. The cure cycle used in manufacturing the panels was described in [1].

Prior to the buckling tests all the specimens were completely dried at $366 \mathrm{~K}$ in a desiccator. The specimens were then placed in environmental chambers [2] in which the temperature and the relative humidity were kept constant at $366 \mathrm{~K}$ and $100 \%$. The specimens were kept in the chambers until the moisture content (weight gain) reached the required level, i.e. until the specimen was fully saturated or until the moisture contents reached $1 / 3$ or $2 / 3$ of the fully saturated value. At $1 / 3$ and $2 / 3$ saturation the moisture distribution was nonuniform inside the specimen. The moisture distribution at these saturation levels was given by Shen and Springer [1]

The buckling moduli were determined using a $10,000 \mathrm{lb}$ capacity Instron machine (Model TTCLM 14). At the start of each test the specimen was placed between two $15.3 \mathrm{~cm}$ diameter smooth metal discs attached to the Instron machine. The ends of the specimen were not restrained in any other way. The specimen was compressed along its length at a cross-head speed of $1.27 \mathrm{~mm} \mathrm{~min}^{-1}$ $(0.05 \mathrm{in} / \mathrm{min})$. The load was recorded continuously during the test. As the specimen was compressed the load increased to a peak. The load then decreased and levelled off, remaining nearly constant with displacement, as shown in Figure 1. The value of this constant load, designated as the critical load $P_{c r}$, is related to the buckling modulus by the expression [3]

$$
P_{c r}=\frac{\pi^{2} I E_{b}}{L^{2}}
$$

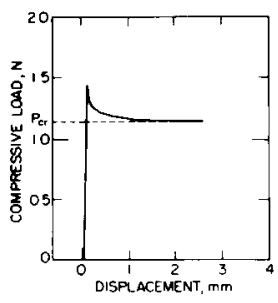

Figure 1. Graph of compressive load versus cross - head displacement in a ty pical buckling test. $90^{\circ}$ specimen at $300 \mathrm{~K}$ and $0 \%$ mois. ture content. where $E_{b}$ is the buckling modulus, $I$ is the moment of inertia of the cross sectional area $(I=$ $\left.b h^{3} / 12\right)$ and $L$ is the length of the specimen.

By rewriting equation (1) in terms of the critical stress $\sigma_{c r}$, we obtain

$$
\sigma_{c r}=\frac{P_{c r}}{b h}=\frac{\pi^{2} h^{2} E_{b}}{12 L^{2}}
$$

In order to evaluate $E_{b}$ for a given environmental condition, a large number of buckling tests were performed using specimens of different lengths. For each environmental condition at least 12 buckling tests were performed using specimens of lengths 56,89 , and $172 \mathrm{~mm}$. At room temperature $(300 \mathrm{~K}, 0 \%$ moisture content) 25 specimens with lengths ranging between $36 \mathrm{~mm}$ and $318 \mathrm{~mm}$ were tested. The buckling modulus was then determined as follows.

The experimental error $(\epsilon)$ in the data is defined as 


$$
\epsilon=\sigma_{c r}-\frac{\pi^{2} h^{2} E_{b}}{12 L^{2}}
$$

For $N$ number of tests, the sum of the squares of the errors $S$ is

$$
S=\sum_{i=1}^{N}\left(\epsilon_{i}\right)^{2}
$$

or

$$
S=\sum_{i=1}^{N}\left(\sigma_{c r_{i}}-\frac{\pi^{2} h^{2} E_{b}}{12 L_{i}^{2}}\right)^{2}
$$

The subscript $i$ denotes the $i$ th test. The value of $E_{b}$ which makes $S$ a minimum is taken as the buckling modulus. Differentiating equation (5) with respect to $E_{b}$ yields

$$
\frac{d S}{d E_{b}}=\sum_{i=1}^{N} 2\left(\sigma_{c r_{i}}-\frac{\pi^{2} h^{2} E_{b}}{12 L_{i}^{2}}\right)\left(-\frac{\pi^{2} h^{2}}{12 L_{i}^{2}}\right)
$$

By equating equation (6) to zero and solving for the value of $E_{b}$, we obtain the required value of $E_{b}$

$$
E_{b}=\frac{12}{\pi^{2} h^{2}} \sum_{i=1}^{\sum_{i=1}^{N} \frac{\sigma_{c r_{i}}}{L_{i}^{2}}}
$$

It is noted that equation (2) may be written in the form

$$
\log \sigma_{c r}=\log \frac{\pi^{2} h^{2} E_{b}}{12}-2 \log L
$$

According to this equation, on a $\log \sigma_{c r}$ versus $\log L$ plot, the data should fall on a straight line of slope-2. In order to check the accuracy of the present data, all the data were plotted on such a graph. For all test conditions, the data followed closely a straight line of slope-2. A typical set of results is shown in Figure 2.

During each buckling test the specimen was maintained at the desired temperature by an infrared heat lamp. The temperature of the specimen was measured by a copper-constantan thermocouple attached to the surface of the specimen. The moisture content of the environment was not controlled during the buckling test, and hence some drying of the outer layer of the specimen might have occurred 
during the test. The thickness of the layer affected by the drying and the amount of moisture lost during this drying was calculated, and was reported in reference [1] .

\section{RESULTS*}

The effects of temperature and moisture content on the buckling modulus of

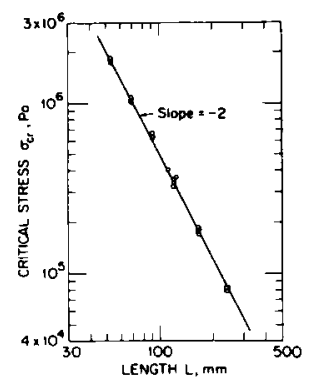

Figure 2. Graph of $\log \sigma_{\text {cr }}$ versus $\log L$ for $90^{\circ}$ specimens at $300 \mathrm{~K}$ and $0 \%$ moisture content.

T300/1034 were determined according to the test procedures described in the previous section. The results in Figure 3 show that for $0^{\circ}$ and $\pi / 4$ laminates the modulus is unaffected either by temperature or by moisture content. The slight decrease $(\sim 5 \%)$ in the buckling modulus for fully saturated specimens is within the range of the scatter of the data. For $90^{\circ}$ laminates the buckling modulus seems to be insensitive to changes in temperature and moisture content as long as the temperature is in the range of $195 \mathrm{~K}-300 \mathrm{~K}$. However, in the temperature range $300 \mathrm{~K}-450 \mathrm{~K}$ the buckling modulus is strongly influenced by both the temperature and the moisture content.

A survey was also made of all the existing data on the effects of temperature and moisture content on the tensile and compressive moduli of composite materials.

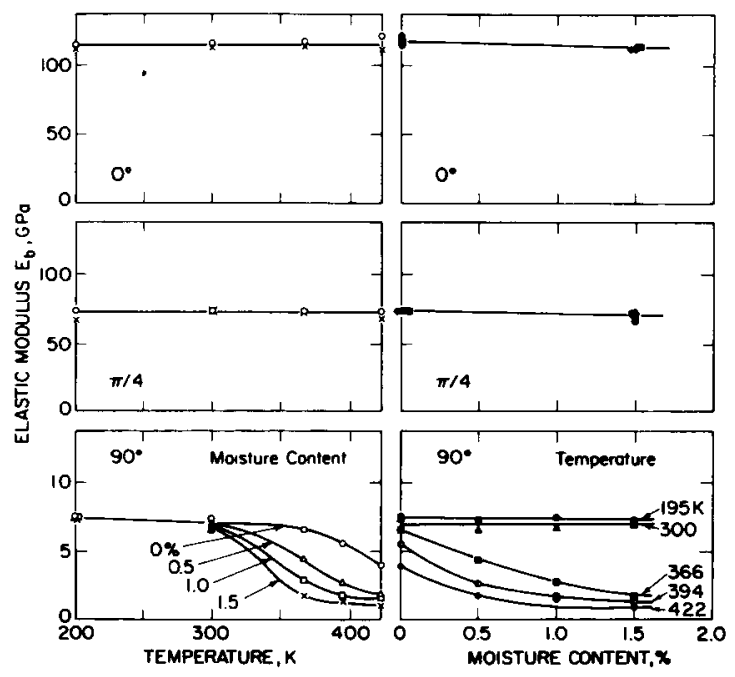

Figure 3. Buckling modulus of Thornel 300/Fiberite 1034 as a function of temperature and moisture content. Present data.

*Note: $1 \mathrm{GPa}=1.45 \times 10^{5} 1 \mathrm{bf} / \mathrm{in}^{2}$. 
The results of this survey are presented in Figures 4-25. In addition, in Table 1 a brief summary of all the data is given, including the type of material, the parameters varied, the general trend in the results, and the appropriate references. All those experiments known to the authors were included in the survey in which the

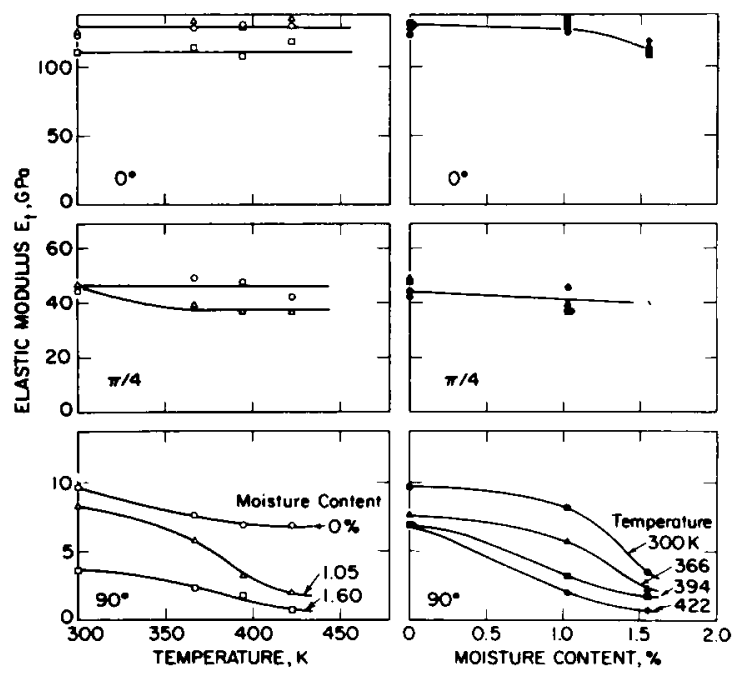

Figure 4. Tensile modulus of Hercules AS-5/350/ as a function of temperature and moisture content. Data of Browning et al, $1976 / 5 /$.
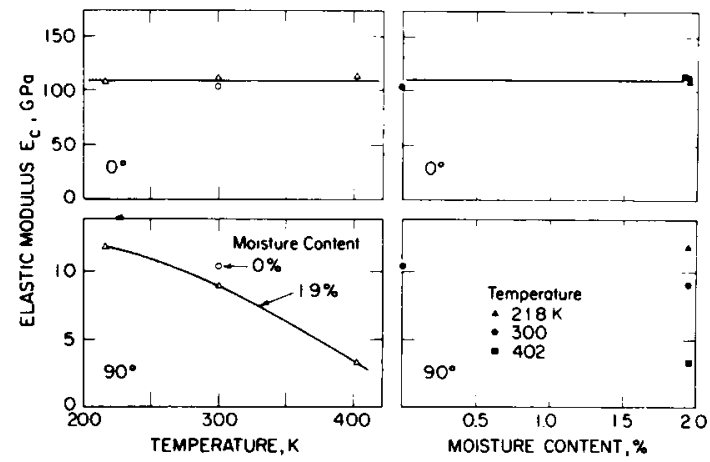

Figure 5. Tensile modulus of Hercules AS-5/3501 as a function of temperature and moisture content. Data of Verette, $1975,[6]$. 
test conditions were either specified completely or could be assessed from the

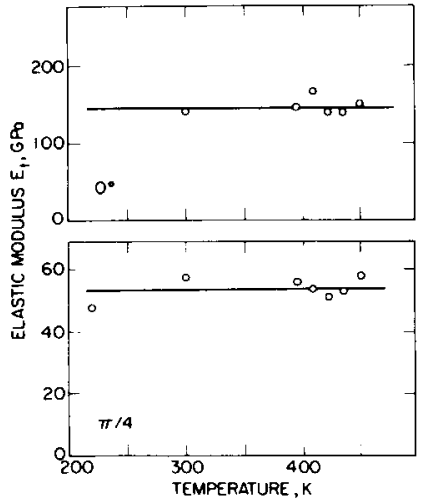

Figure 6. Dry longitudinal and quasi-isotropic tensile moduli of Hercules AS-5/3501 as a function of temperature. Data of Kerr et al $1975 / 7 /$. reports. Those test results where the environmental conditions were not completely identified were excluded. As can be seen from Figures 4-25 there is considerable scatter in the data. Furthermore, in certain cases only 2 or 3 data points were obtained. Nevertheless, the general trends in the behavior of previously obtained tensile and compressive moduli (Figures 4-25) are similar to the behavior of the buckling moduli obtained in the present study (Figure 3).

Figures 3-25 may be used to evaluate the effects of temperature and moisture content on the tensile, compressive and buckling moduli of different composites. Figures 3-25 also indicate the conditions where data are lacking.

It is finally noted that the effects of temperature and moisture content on the three moduli $\left(E_{t,} E_{c}, E_{b}\right)$ are very similar to those on the ultimate tensile strength [1].
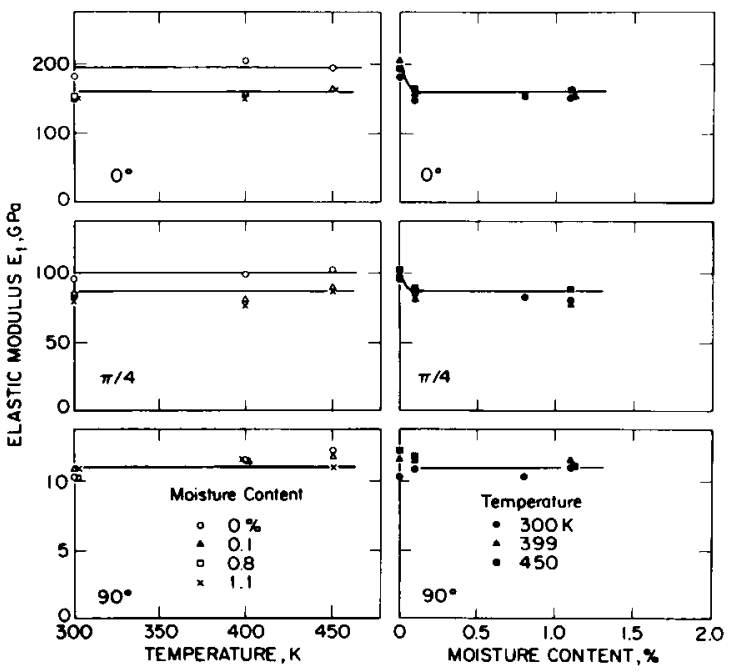

Figure 7. Tensile modulus of Thornel 300/Narmco 5208 as a function of temperature and moisture content. Data of Hofer et al, 1975 [8]. 


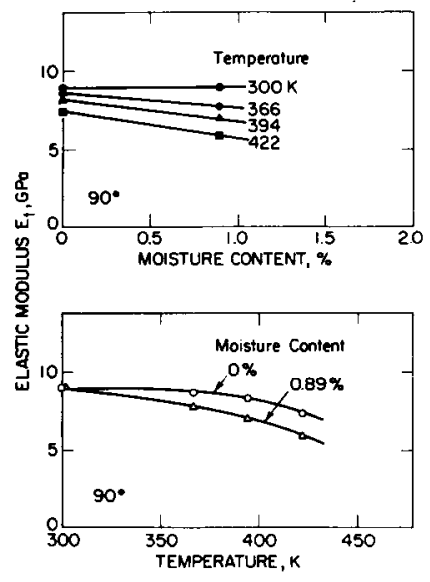

Figure 8. Transverse tensile modulus of Thornel $300 /$ Narmco 5208 as a function of temperature and moisture content. Data of Husman, 1976 [9].

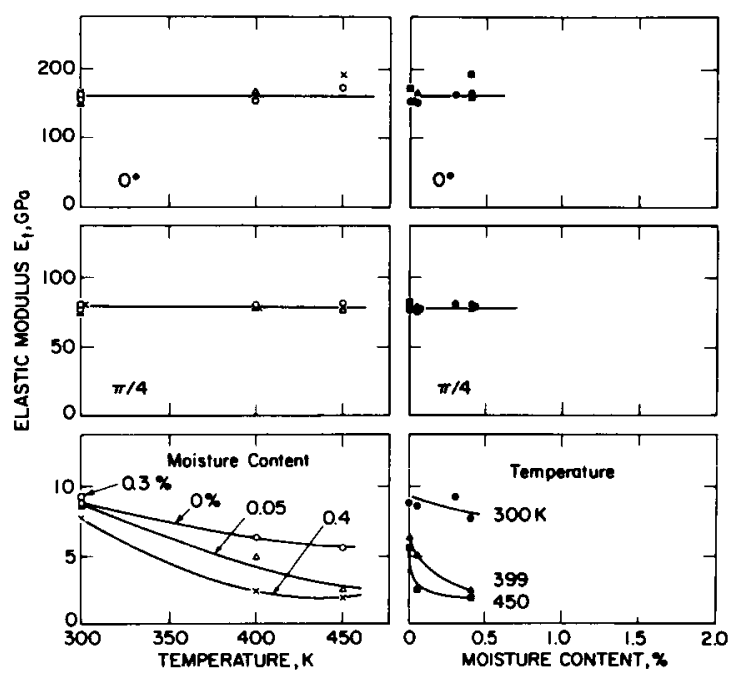

Figure 9. Tensile modulus of Modmor II/Narmco 5206 as a function of temperature and moisture content. Data of Hofer et al, 1974/10/.

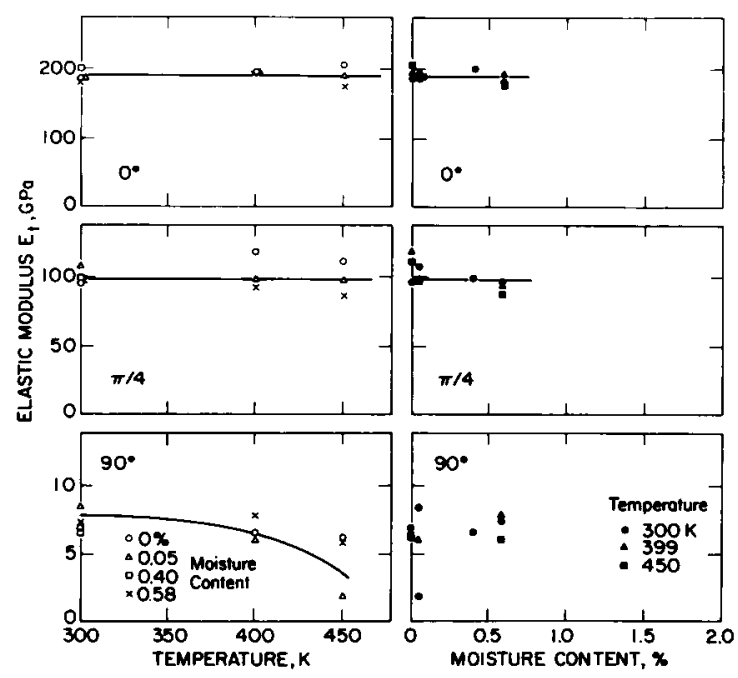

Figure 10. Tensile modulus of Courtaulds HMS/Hercules $3002 M$ as a function of temperature and moisture content. Data of Hofer et al, 1974 [10].

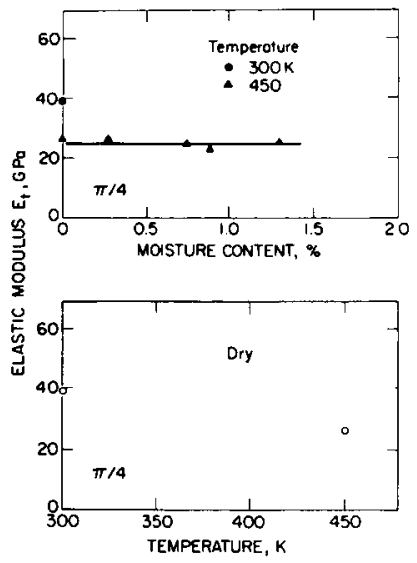

Figure 11. Quasi-isotropic tensile modulus of HT-S/ERLA-4617as a function of temperature and moisture content. Data of Browning, $1972[11]$. 


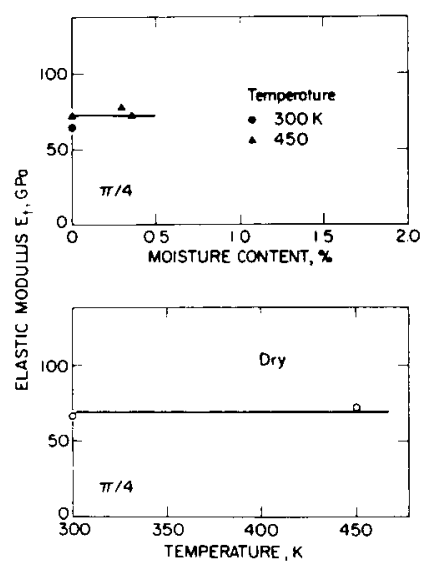

Figure 12. Quasi-isotropic tensile modulus of HT-S/Fiberite X-91I as a function of temperature and moisture content. Data of Browning, $1972 / 11 /$.

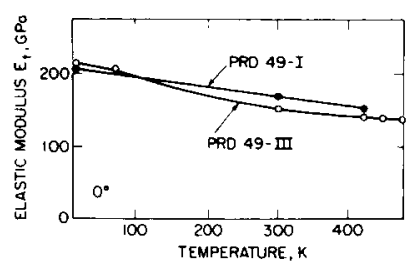

Figure 14. Dry longitudinal tensile modulus of PRD-49/ERLB-4617 as a function of temperature. Data of Hanson, 1972 /121.

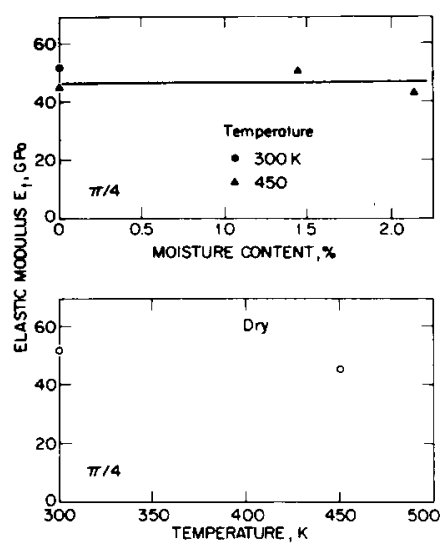

Figure 13. Quasi-isotropic tensile modulus of HT-S/UCC X-2546 as a function of temperature and moisture content. Data of Browning, $1972[11]$.

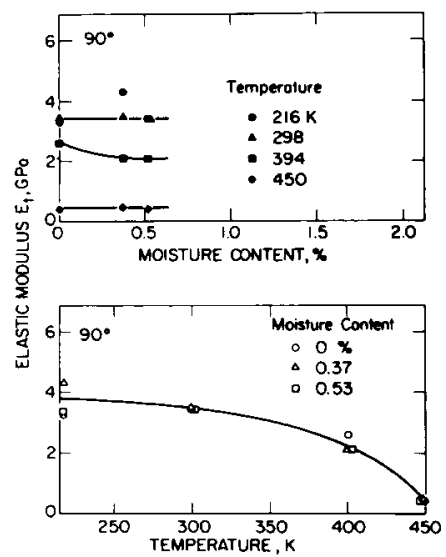

Figure 15. Transverse tensile modulus of HT $-S / / 8183 / 137 \cdot N D A$ $\left.B F_{3}: M E A\right)$ as a function of temperature and moisture content.

Data of Hertz, 1973 [13]. 


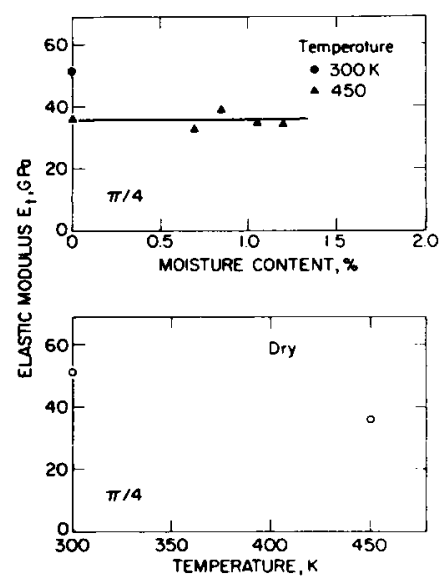

Figure 16. Quasi-isotropic tensile modulus of HT-S/Hy'sol ADX-516 as a function of temperature and moisture content. Data of Browning, $1972 / 11 /$.

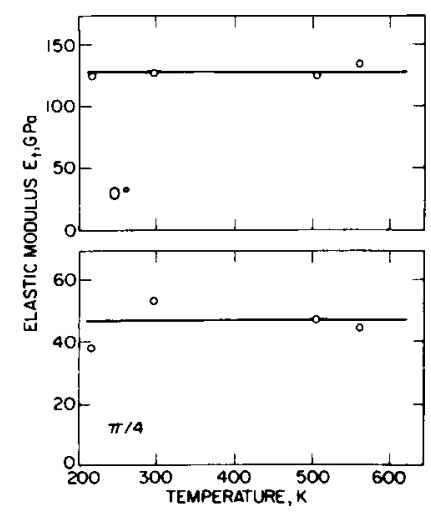

Figure 17. Dry longitudinal and quasi-isotropic tensile moduli of HT.S/7lO Polyimide as a function of temperature. Data of Kerr et al. $1975 / 7 /$.

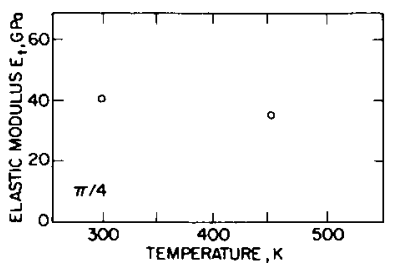

Figure 18. Dry quasi-isotropic tensile modulus of HT-S/PI $3 N$ Polyimide as a function of temperature. Data of Browning, $1972 / 11 /$.

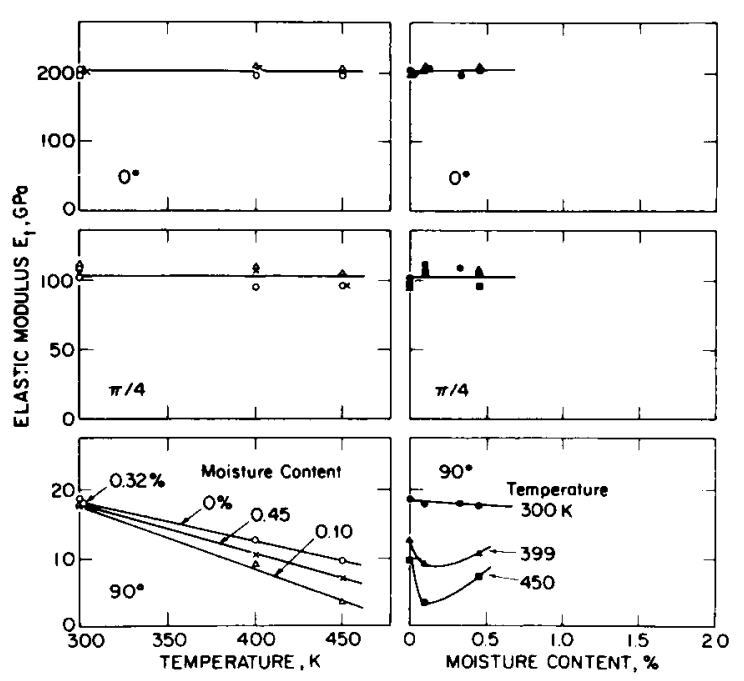

Figure 19. Tensile modulus of Boron/AVCO 5505 as a function of temperature and moisture content. Data of Hofer et al, $1974 / 10 /$. 


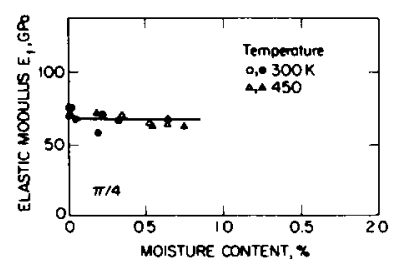

Figure 20. Quasi-isotropic tensile modulus of Boron/Narmco 5505 as a function of temperature and moisture content. Data of Browning, $1972[11] . \circ \Delta:$ post-cured specimen, $\bullet$ : not post-cured specimen.

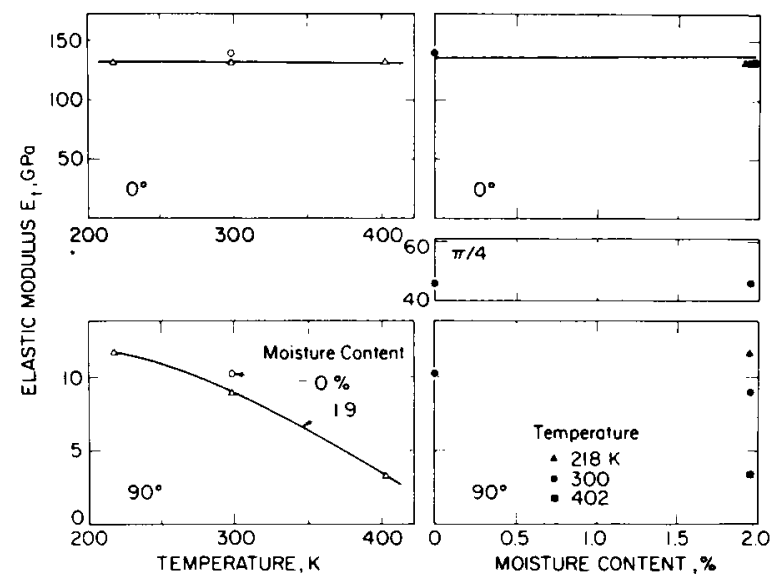

Figure 21. Longitudinal and transverse compressive moduli of Hercules HS-5/3501 as a function of temperature and moisture content. Data of Verette, 1975 /6].

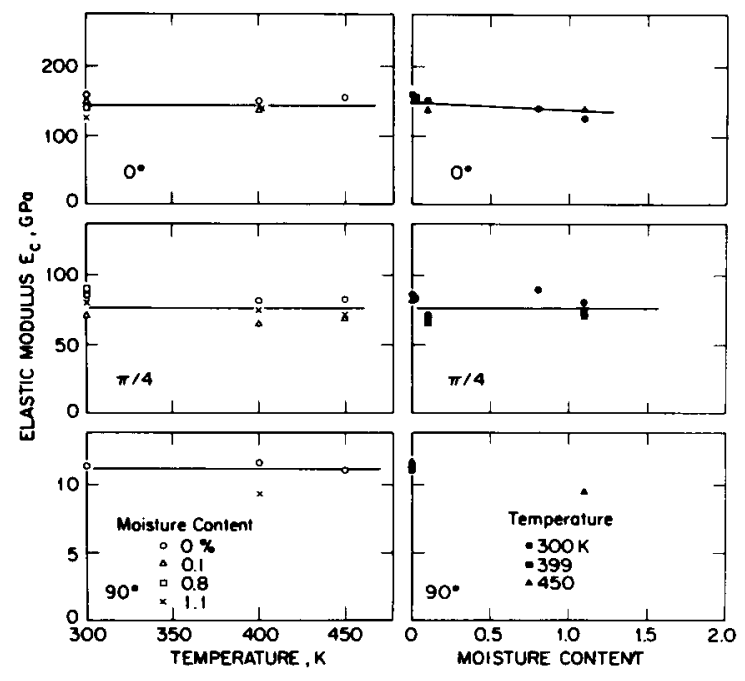

Figure 22. Compressive modulus of Thornel 300/Narmco 5208 as a function of temperature and moisture content. Data of Hofer et al, 1975 [8]. 

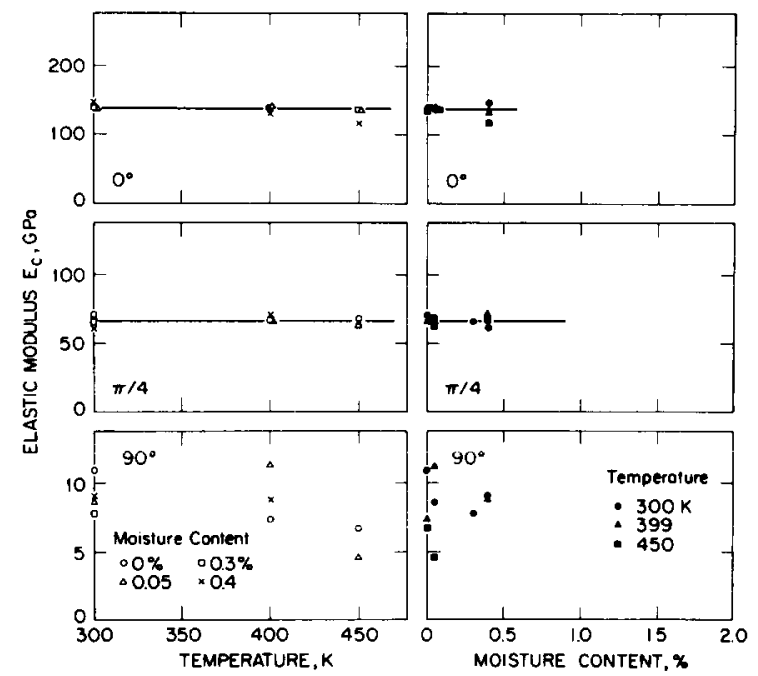

Figure 23. Compressive modulus of Modmor II/Narmco 5206 as a function of temperature and moisture content. Data of Hofer et al, 1974 /10/.

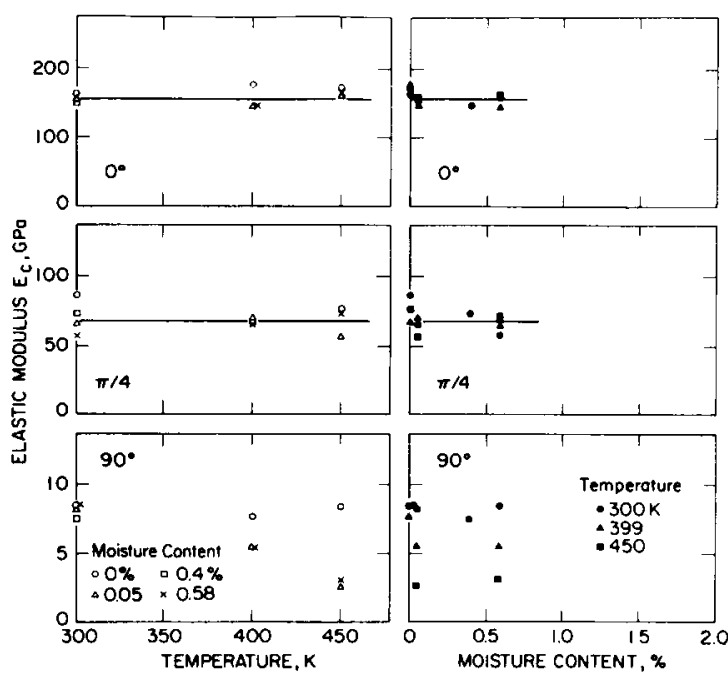

Figure 24. Compressive modulus of Courtaulds HMS/Hercules $3002 M$ as a function of temperature and moisture content. Data of Hofer et al, 1974 /10/. 


\section{Environmental Effects on the Elastic Moduli}

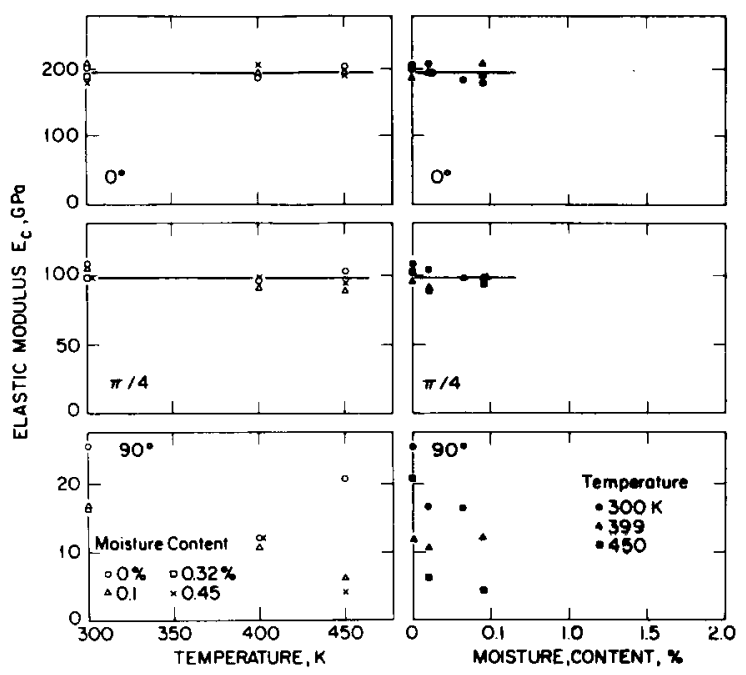

Figure 25. Compressive modulus of Boron/AVCO 5505 as a function of temperature and moisture content. Data of Hofer et al, 1974 [10].

It is emphasized again that the results presented illustrate the trend in the buckling moduli. In addition to temperature and humidity, other parameters such as cure cycle, temperature history (thermal spikes), and loading history may influence the absolute value of the buckling modulus.

\section{ACKNOWLEDGMENTS}

This work was supported by the United States Air Force Materials Laboratory, Air Force Systems Command, Wright-Patterson Air Force Base, Dayton, Ohio.

\section{NOMENCLATURE}

$b \quad$ width of specimen $(\mathrm{mm})$

$\epsilon$ experimental error defined in equation (3) $(\mathrm{Pa})$

$E_{b}$ buckling modulus $(\mathrm{Pa})$

$E_{c}$ compressive modulus $(\mathrm{Pa})$

$E_{t}$ tensile modulus $(\mathrm{Pa})$

$h$ thickness of specimen (mm)

I moment of inertia of the cross sectional area $\left(\mathrm{mm}^{4}\right)$

$L$ length of specimen (mm)

$N$ number of buckling tests (dimensionless)

$P_{c r}$ critical buckling load (N) 
$S$ sum of the squares of the errors defined in equation (4) $\left(\mathrm{Pa}^{2}\right)$

$\sigma_{c r}$ critical buckling stress $(\mathrm{Pa})$

\section{REFERENCES}

1. C. H. Shen and G. S. Springer, "Effects of Moisture and Temperature on the Tensile Strength of Composite Materials," J. Composite Materials, Vol. II (1977), p. 2.

2. G. S. Springer and C. H. Shen, "Moisture Absorption and Desorption of Composite Materials," Technical Report AFML-TR-76-102, June 1976, Air Force Materials Laboratory, Air Force Systems Command, Wright-Patterson Air Force Base, Dayton, Ohio.

3. A. Chajes, Principles of Structural Stability Theory, Prentice-Hall (1974).

4. C. H. Shen and G. S. Springer, "Moisture Absorption and Desorption of Composite Materials," J. Composite Materials, Vol. 10 (1976), p. 2.

5. C. E. Browning, G. E. Husman, and J.M. Whitney, "Moisture Effects in Epoxy Matrix Composites," Composite Materials: Testing and Design, ASTM, STP 617 (1976).

6. R. M. Verette, "Temperature/Humidity Effects on the Strength of Graphite/Epoxy Laminates," AIAA Paper No. 75-1011, AIAA 1975 Aircraft Systems and Technology Meeting, Los Angeles, California, August 4-7, 1975.

7. J. R. Kerr, J. F. Haskins and B. A. Stein, "Program Definition and Preliminary Results of a Long-Term Evaluation Program of Advanced Composites for Supersonic Cruise Aircraft Applications," Environmental Effects on Advanced Composite Materials, ASTM, STP 602 (1975), p. 3.

8. K. E. Hofer, Jr., D. Larsen and V. E. Humphreys, "Development of Engineering Data on the Mechanical and Physical Properties of Advanced Composite Materials," Technical Report AFML-TR-74-266, February, 1975, Air Force Materials Laboratory, Air Force Systems Command, Wright-Patterson Air Force Base, Dayton, Ohio.

9. G. E. Husman, "Characterization of Wet Composite Materials," Presented at the Mechanics of Composites Review, Bergamo Center, Dayton, Ohio, January 28-29, 1976.

10. K. E. Hofer, Jr., N. Rao and D. Larsen, "Development of Engineering Data on the Mechanical and Physical Properties of Advanced Composite Materials," Technical Report AFMLTR-72-205 Part II, February 1974, Air Force Materials Laboratory, Air Force Systems Command, Wright-Pat terson Air Force Base, Dayton, Ohio.

11. C. E. Browning, "The Effects of Moisture on the Properties of High Performance Structural Resins and Composites," Technical Report AFML TR-72-94, September 1972, Air Force Materials Laboratory, Air Force Systems Command, Wright-Patterson Air Force Base, Dayton, Ohio.

12. M. P. Hanson, "Effect of Temperature on the Tensile and Creep Characteristics of PRD 49 Fiber/Epoxy Composites," Composite Materials in Engineering Design, B. R. Norton ed., Proceedings of 6th St. Louis Symposium, May 11-12, 1972, p. 717. Published by The American Society for Metals.

13. J. Hertz, "Investigation into the High-Temperature Strength Degradation of Fiber-Reinforced Resin Composite During Ambient Aging," Convair Aerospace Division, General Dynamics Corporation, Report No. GDCA-DBG73-005, Contract NAS8-27435, June 1973. 